\title{
Preparation and Structural Characterization of 0-Acetyl Agarose with Low Degree of Substitution
}

\author{
Rosangela B. Garcia and Rosangela R. L. Vidal \\ Departamento de Química, UFRN, Brasil
}

\section{Marguerite Rinaudo \\ Centre de Recherches sur les Macromolécules Végétales, Grenoble, France}

\begin{abstract}
Among the biodegradable polymers, the polysaccharides have been found to be promising carriers for bioactive molecules. From a general standpoint, they present several reactive groups, such as hydroxyl, carboxyl and amine, that can be modified in a number of ways, giving rise to suitable devices for controlled release. In this paper, agarose was submitted to O-acetylation reactions under heterogeneous conditions, using acetic anhydride and pyridine, aiming to observe the effect of acetyl groups on the agarose properties. The products were characterized by Infrared and ${ }^{1} \mathrm{H}$ NMR spectroscopies. In the range of average acetylation degrees (DA) $0.07-0.48$, the polymers presented partial solubility in boiling water and in common organic solvents. The ${ }^{1} \mathrm{H}$ NMR spectra presented evidences of non-homogeneous acetyl group distribution along the chains, as concluded from the solubility of only one of the fractions with DA $<0.09$, in boiling water .
\end{abstract}

Keywords: Agarose, o-acetyl agarose, acetylation.

\section{Introduction}

Agarose is a polysaccharide obtained from red algae of the Rhodophyceae class which can be considered as an alternating copolymer of $\beta$-D-galactopyranosyl and 3,6-anhydro- $\alpha$-L-galactopyranosyl units (Figure 1), linked in the backbone by $1 \rightarrow 3$ and $1 \rightarrow 4$ glycosidic bonds, respectively ${ }^{[1]}$. It has been extensively used in pharmaceutical and food industries, mainly due to its gelling ability ${ }^{[2,3]}$. Agarose forms thermoreversible gels in water at a concentration as low as $0.1 \%$ and at temperatures considerably below the temperature of gel melting $\left(\mathrm{T}_{\text {gelation }} \sim 40{ }^{\circ} \mathrm{C}\right.$ and $\left.\mathrm{T}_{\text {melting }} \sim 90{ }^{\circ} \mathrm{C}\right)$ depending on the presence of substituents.

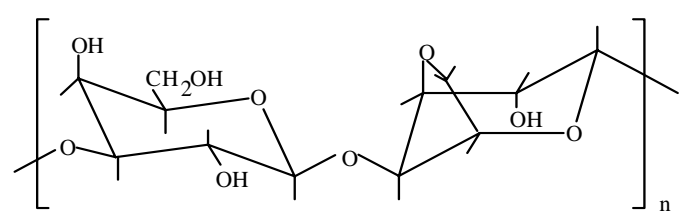

Figure 1. Chemical structure of agarose
During the last decades, a number of studies has been dedicated to the development of systems for controlled release of drugs. A wide range of applications can be envisaged benefiting human beings and animals, in addition to improving agricultural methods. The main goal of such studies is to obtain prolonged and constant delivering rate, reduced number of drug administrations and minimized risk of side effects related to doses above toxic levels ${ }^{[4-5]}$. Both synthetic ${ }^{[6-13]}$ (polylactic acid, polyglycolic acid, poly ( $\varepsilon$-caprolactone) among others) and natural polymers ${ }^{[14,15]}$ (mainly collagen, gelatin and albumin) have been used.

Different methods have been proposed to prepare sustained-release formulations for pharmaceutical applications. From a general standpoint, they are based either on the physical incorporation of active agents into a suitable polymeric matrix or on the synthesis of pharmacologically active polymers, in which the drug can either be part of the polymeric backbone or be bound to a side chain ${ }^{[16-28]}$.

To whom correspondence should be addressed: Rosangela B. Garcia, Departamento de Química, Universidade Federal do Rio Grande do Norte, C.P. 1662, CEP: 59078-970, Natal, RN. E-mail: balaban@linus.quimica.ufrn.br 
In the case of physical incorporation, a drug core can be surrounded by a polymeric film or, alternatively, it can be homogeneously distributed in a polymer matrix. Drug release can take place in a number of ways, including diffusion throughout the polymer film or matrix; degradation/dissolution of bioerodible polymers, or swelling of the polymeric matrix with formation of pores through which the drug can flow ${ }^{[28]}$.

The efficiency of drug entrapment as well the rate of delivering depend on both the drug and polymer physicochemical properties. Promising results on slow drug releasing and high drug loading have been obtained for lipophilic drugs loaded into water insoluble polymers ${ }^{[16,22,27]}$. Nevertheless, contrary to free drug systems, the encapsulated drug is not promptly available to the biological system, regardless of the nature of the polymeric carrier used.

Natural polymers are preferable for human applications, as they are usually more safe and biocompatible. Due to their biodegradation and common solubility in aqueous medium, they are suitable for bioerodible drug delivery systems. However, the use of a water-soluble polymer as a major constituent produces a highly hydrophilic polymer matrix completely permeated by water, increasing the rate of drug release ${ }^{[18,23]}$. Therefore, crosslink reactions are frequently performed to avoid (or at least minimize) the solubility of the polymer in aqueous environments ${ }^{[19,24,29]}$.

In order to evaluate the possibility of using acetylation reactions to obtain less hydrophylic agarose derivatives with potential applications in controlled drug release, a study of structural characterization and solubility properties was performed on O-acetyl agarose with low degree of substitution.

\section{Experimental}

\section{Materials}

Agarose was kindly supplied by CIALGAS Companhia Industrial de Algas (São Paulo, Brazil), and was used as received. Acetic anydride, pyridine and solvents such as dimethylformamide (DMF), dimethylacetamide (DMA), chloroform, methylisobuthylketone, dimethylsulphoxide (DMSO) and 1,2dichloroethane were of pure grade and used as received.

\section{Acetylation reactions}

Two grams of agarose were dispersed in $80 \mathrm{~mL}$ of acetic anhydride (96\%) and pyridine (4\%) at room temperature. Just in the beginning of reactions, an ice bath was used to control the medium temperature. The reactions were carried out for $30 \mathrm{~min}, 2 \mathrm{~h}, 4 \mathrm{~h}$, $10 \mathrm{~h}$ and $20 \mathrm{~h}$, under constant stirring in heterogeneous conditions. At the end of reaction, ground ice was added. The insoluble acetylated samples were recovered by filtration and washed with cold water and methanol. The purification was performed by reflux of methanol for $5 \mathrm{~h}$ in a Soxhlet extractor. Afterwards, the product was dried under vaccum for $24 \mathrm{~h}$. The yield of polymer recovery was always higher than $70 \%$.

\section{Characterization of 0 -acetyl agarose}

\section{Infrared Spectroscopy}

FTIR spectra were obtained in the film form on a MIDAC Prospect Spectrometer, in the frequency range of $4000-500 \mathrm{~cm}^{-1}$. The polymers were dissolved in DMA at $5 \mathrm{~g} / \mathrm{L}$ concentration; after filtration, the solutions were placed on teflon dishes and maintained for about $72 \mathrm{~h}$ at $50{ }^{\circ} \mathrm{C}$ for complete evaporation of solvent and formation of the film.

\section{${ }^{1}$ H NMR Spectroscopy}

${ }^{1} \mathrm{H}$ NMR spectra were obtained using a $300 \mathrm{MHz}$ spectrometer from Bruker, at $80{ }^{\circ} \mathrm{C}$, after dissolution of the samples in dimethyl- $\mathrm{d}_{6}$-sulphoxide $\left(\left[\mathrm{CD}_{3}\right]_{2} \mathrm{SO}\right)$.

\section{Degree of acetylation (DA)}

The average degree of substitution was determined from ${ }^{1} \mathrm{H} \mathrm{NMR}$, using the ratio of integral signal at 2.0 ppm $\left(\mathrm{CH}_{3} \mathrm{COO}-\right)$ and that of the two separated signals between 5.0 and $5.3 \mathrm{ppm}$ which were used as internal standard on the basis of the integral of all the osidic protons; each of these two signals represents one proton.

\section{Solubility tests}

The samples were dispersed in the solvents DMF, DMA, DMSO, DMA-LiCl 5\%, chloroform, methylisobuthylketone and 1,2-dichloroethane at concentration in the range 5-20 g/L. The dispersions were maintained under stirring overnight at room temperature. The solubility was determined by the residual mass after centrifugation. 


\section{Intrinsic viscosity}

The viscosity measurements were performed in a Ubbelohde capillary $\left(\mathrm{f}=0.58 \mathrm{~mm}\right.$ ) at $25{ }^{\circ} \mathrm{C} \pm 0.1$, using DMSO as solvent. The viscometer was capped with a column of silica to avoid atmospheric moisture absorption by the solvent.

\section{Results and discussion}

The infrared spectroscopy of agarose and O-acetyl agarose samples are presented in Figure 2. The principal bands for agarose were observed at $3395 \mathrm{~cm}^{-1}$ (OH, axial deformation), $2904 \mathrm{~cm}^{-1}(\mathrm{CH}$, axial deformation), 1158 and $1071 \mathrm{~cm}^{-1}$ (C-O, axial deformation), $930 \mathrm{~cm}^{-1}$ (characteristic of 3,6-anhydrogalactose) and $891 \mathrm{~cm}^{-1}$ (attributed to $\mathrm{CH}$ angular deformation of $\beta$ anomeric carbon). The band at $1741 \mathrm{~cm}^{-1}$ not present in agarose spectrum was attributed to the $\mathrm{C}=\mathrm{O}$ group and directly connected to the chemical modification.

In reality, depending on the species of marine red algae and the process of extraction used, several substituents, such as methyl ethers, sulphate esters and pyruvate ketals can be found in agarose [30,31]; this

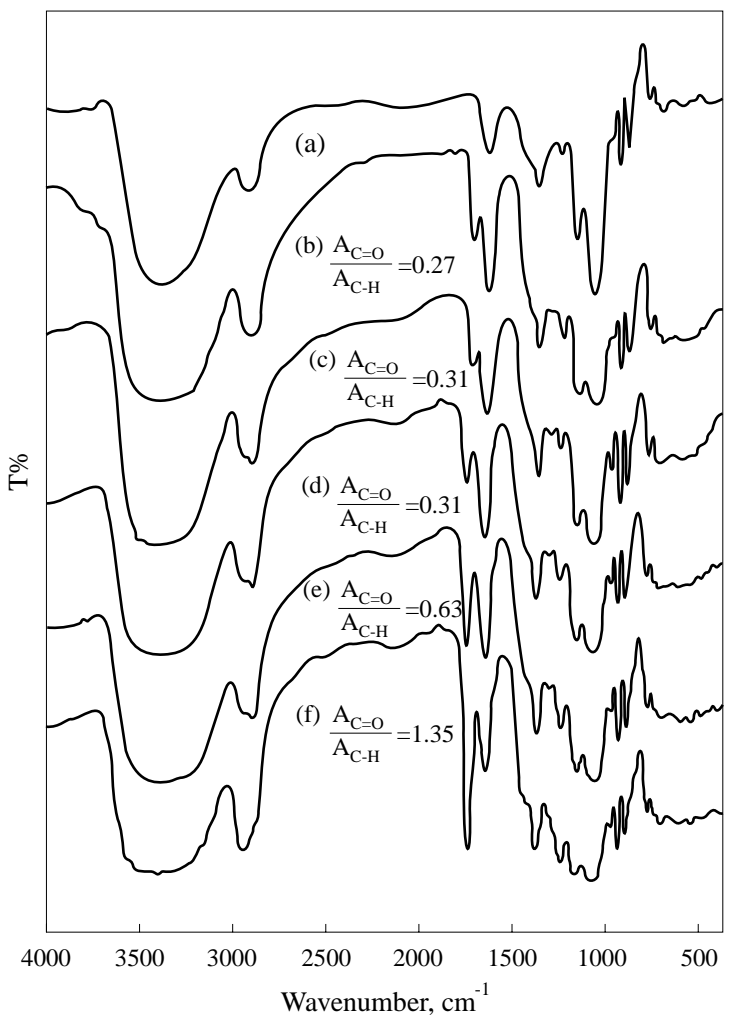

Figure 2. Infrared spectra of agarose (a) and O-acetyl agarose: AGA20h (b); AGA0.5h (c); AGA2h (d); AGA10h (e); AGA4h (f). can be deduced from IR spectrum but it was not our purpose to identify these groups. The comparison of agarose and acetylated agarose spectra shows no modification but only the appearence of the $\mathrm{C}=\mathrm{O}$ band considered previously.

Then, the acetylation of agarose was followed by Infrared spectroscopy using the characteristic band of acetyl groups at $1740-1725 \mathrm{~cm}^{-1}(\mathrm{C}=\mathrm{O}$, axial deformation). A quantitative measurement of acetylation was performed taking into account the absorbance of $\mathrm{C}=\mathrm{O}$ band at $1740-1725 \mathrm{~cm}^{-1}$ and the $\mathrm{C}-\mathrm{H}$ band at $2904 \mathrm{~cm}^{-1}$ (Figure 3a) or O-H band at 3395 $\mathrm{cm}^{-1}$ (Figure 3b) as internal standard, according the baseline method. Figure 3 shows the baselines used for these determinations. It was observed a maximum of $\mathrm{A}_{\mathrm{C}=\mathrm{O}} / \mathrm{A}_{\mathrm{C}-\mathrm{H}}$ and $\mathrm{A}_{\mathrm{C}=\mathrm{O}} / \mathrm{A}_{\mathrm{O}-\mathrm{H}}$ for the reaction carried out for $4 \mathrm{~h}$ and smaller ratios with the increase of reaction time (10 and 20h). This unexpected behaviour can be related to the reversible character of acetylation reactions or some fractionation occurring during the step of purification due to change in solubility and heterogeneity of the reaction.

Figure 4 shows the ${ }^{1} \mathrm{H}$ NMR spectrum of agarose sample used in this work (a) and in (b) the spectrum obtained for acetylated agarose. From this, it is clear that only slight modifications are observed but the
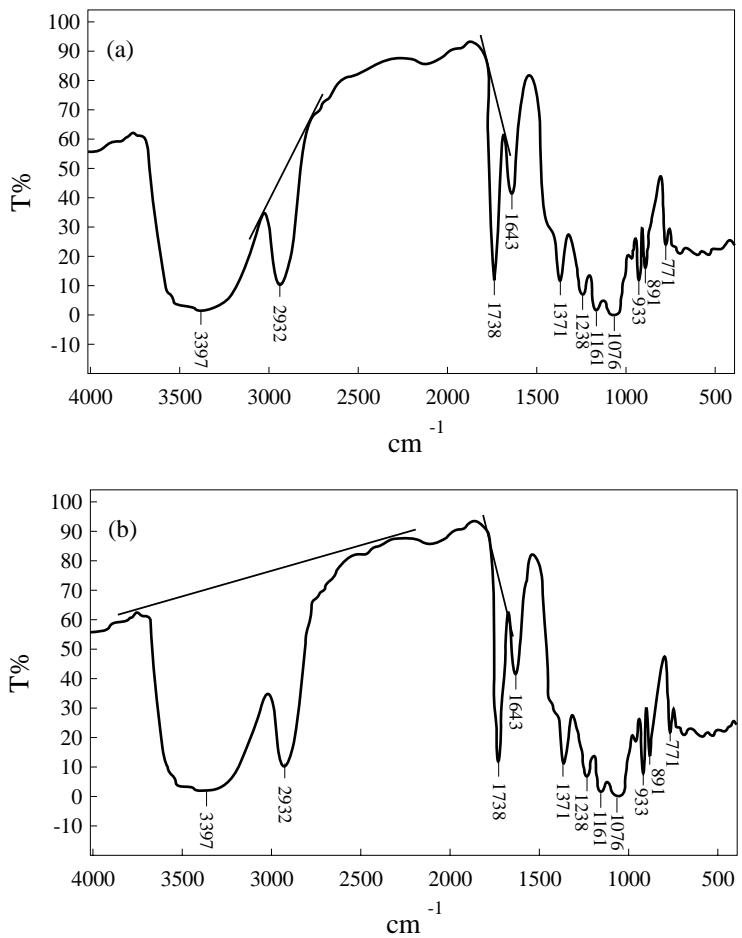

Figure 3. Baselines used for determination of $\mathrm{A}_{\mathrm{C}=\mathrm{O}} / \mathrm{A}_{\mathrm{C}-\mathrm{H}}$ (a) and $\mathrm{A}_{\mathrm{C}=\mathrm{O}}$ / $\mathrm{A}_{\mathrm{O}-\mathrm{H}}(\mathrm{b})$ ratios.

Polímeros: Ciência e Tecnologia, vol. 10, ํㅜ 3, p. 155-161, 2000 


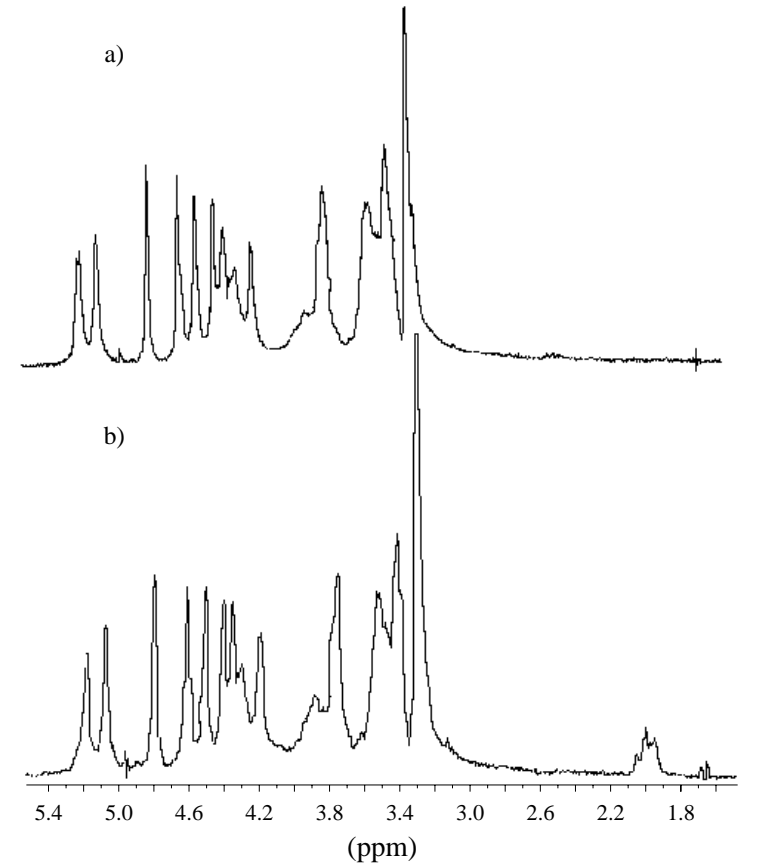

Figure 4. ${ }^{1} \mathrm{H}$ NMR in DMSO at $80{ }^{\circ} \mathrm{C}$ for (a) agarose and (b) acetylated agarose

characteristic signal for the protons of the $-\mathrm{CH}_{3}$ substituent appears around 2ppm .

Figure 5 shows the acetylation pattern of the samples by $\mathrm{H}^{1} \mathrm{NMR}$. Three separate signals between 1.9 and $2.1 \mathrm{ppm}$ were detected individually with the increase of DA, attributed to the methyl -proton groups of O-acetyl substituents in the different positions of repeating units. Similar results have been taken for cellulose acetate in some solvents ${ }^{[32,33]}$. The signal at $2.01 \mathrm{ppm}$ corresponds to the more reactive hydroxyl groups in agarose, probably the primary hydroxyls. As the degree of acetylation increases the signal at $1.94 \mathrm{ppm}$ becomes more significant and the signal at 2.05 ppm maintains its relative intensity.

The determination of average acetylation degree (DA) by the traditional method of acetyl hydrolysis with sodium hydroxide followed by neutralisation titration with hydrochloric acid ${ }^{[34]}$ was not successful for O-acetyl agarose samples, probably due to the removal by alkaline treatment of sulphate groups initially present in agars, giving overestimated values for DA (results not published). The determination of DA per monomeric unit was estimated by the ratio between integration of $-\mathrm{CH}_{3}$ signal on modified samples and the integral $\mathrm{I}_{\mathrm{ref}}$ of the two signals between 5 and 5.3 using the relation $\mathrm{DA}=2 \mathrm{I}_{\mathrm{CH} 3} / 3 \mathrm{I}_{\text {ref }}$. $\mathrm{A}$ relatively good linear relation was obtained between the DA determined by NMR and the ratio $\mathrm{A}_{\mathrm{C}=\mathrm{O}} / \mathrm{A}_{\mathrm{C}-\mathrm{H}}$

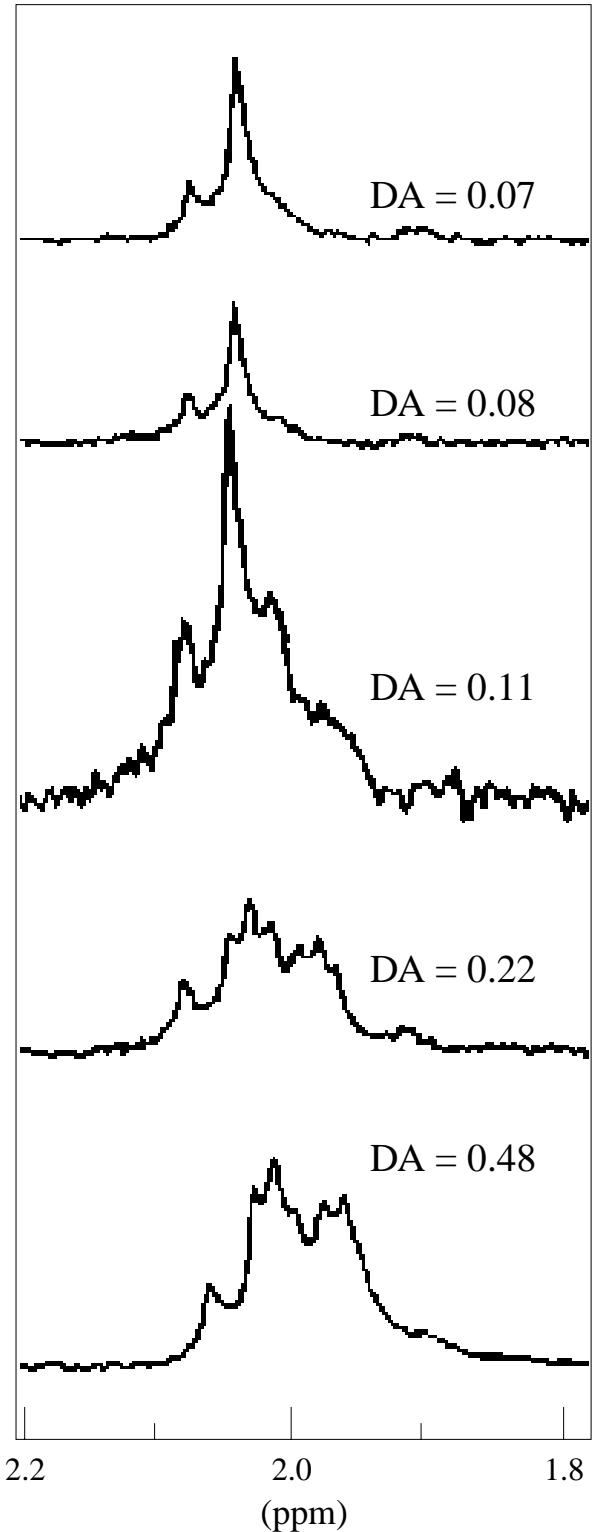

Figure 5. 'H NMR spectra of O-acetyl agarose samples at different degrees of acetylation.

or $\mathrm{A}_{\mathrm{C}=\mathrm{O}} / \mathrm{A}_{\mathrm{OH}}$ (Table 1), as showed in Figure 6. These calibration curves, following the equations

$$
\mathrm{DA}=0.36 \times \mathrm{A}_{\mathrm{C}=\mathrm{O}} / \mathrm{A}_{\mathrm{C}-\mathrm{H}}
$$

and $\mathrm{DA}=0.76 \times \mathrm{A}_{\mathrm{C}=\mathrm{O}} / \mathrm{A}_{\mathrm{O}-\mathrm{H}}$

can be used for determination of average degree of acetylation from the Infrared spectra of O-acetyl agarose samples.

The solubility of agarose and its O-acetyl derivatives is illustrated in Table 2. No direct influence of the DA on solubility was observed for the samples studied. All O-acetyl agarose samples, in the two concentrations used ( 5 and $20 \mathrm{~g} / \mathrm{L}$ ), presented a better solubility in some organic solvents, as chloroform, methylisobuthylketone 
Garcia, R. B. et al. - 0-acetyl agarose with low degree of substitution

Table 1. Degree of acetylation and $\mathrm{A}_{\mathrm{C}=\mathrm{O}} / \mathrm{A}_{\mathrm{C}-\mathrm{H}}$ and $\mathrm{A}_{\mathrm{C}=\mathrm{O}} / \mathrm{A}_{\mathrm{O}-\mathrm{H}}$ ratio for $\mathrm{O}$ acetyl agarose samples.

\begin{tabular}{lccc}
\hline Sample & DA from $\mathbf{N M R}$ & $\mathbf{A}_{\mathrm{C}=\mathbf{0}} / \mathbf{A}_{\mathrm{C}-\mathrm{H}}$ & $\mathbf{A}_{\mathrm{C}=\mathbf{0}} / \mathbf{A}_{\mathbf{O}-\mathbf{H}}$ \\
\hline AGA 0.5h & 0.08 & 0.31 & 0.06 \\
AGA 2h & 0.07 & 0.31 & 0.07 \\
AGA 4h & 0.48 & 1.35 & 0.60 \\
AGA 10h & 0.22 & 0.63 & 0.15 \\
AGA 20h & 0.11 & 0.27 & 0.06 \\
\hline
\end{tabular}

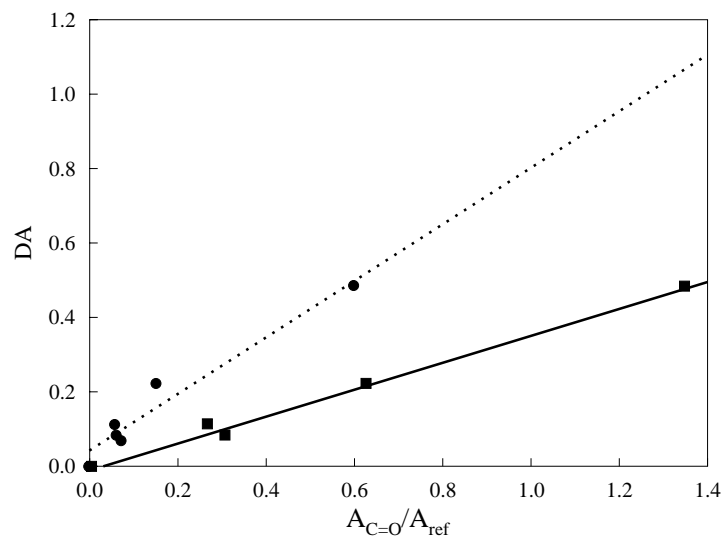

Figure 6. Variation of degree of acetylation (DA) determined from ${ }^{1} \mathrm{H}$ $\mathrm{NMR}$ with the ratio $\mathrm{A}_{\mathrm{C}=\mathrm{O}} / \mathrm{A}_{\mathrm{C}-\mathrm{H}}(<)$ or $\mathrm{A}_{\mathrm{C}=\mathrm{O}} / \mathrm{A}_{\mathrm{O}-\mathrm{H}}(=)$ for O-acetyl agarose samples.

and 1,2-dichloroethane, than underivatized agarose. In addition, the solubility of these samples in boiling water was sensibly diminished.

The ability of O-acetyl agarose samples to form gel in water was also evaluated. After solubilization of the samples at $10 \mathrm{~g} / \mathrm{L}$ concentration in boiling water, the insoluble fraction (and perhaps more substituted)
Table 2. Solubility of agarose and O-acetyl agarose $\mathrm{a}^{\mathrm{a}}$.

\begin{tabular}{lcc}
\hline \multirow{2}{*}{ Solvent } & \multicolumn{2}{c}{ Sample } \\
\cline { 2 - 3 } & Agarose & O-acetyl agarose* \\
\hline DMF & + & + \\
DMA & + & + \\
Chloroform & - & \pm \\
1,2-dichoro ethane & - & \pm \\
Methylisobuthylketone & - & \pm \\
DMSO & + & + \\
Boiling water & + & \pm \\
\hline All degree of substitution. & &
\end{tabular}

was separated through hot filtration. Afterwards, the clear solution was cooled down to room temperature. Comparing the gels obtained from agarose and O-acetyl agarose samples at $10 \mathrm{~g} / \mathrm{L}$ (Table 3 ), with respect to how easily they break as hand pressed, the formation of weaker gels from acetylated samples especially with low DA (0.07 and 0.08) was observed. As the degree of acetylation increases, the gels become stronger, but yet weaker than initial agarose gels. To understand better these results, the intrinsic viscosity (Table 3 ) was determined for all samples.

The intrinsic viscosity in a good solvent (DMSO) for all O-acetyl agarose samples were smaller than for agarose. This means a decrease in molecular weight with the chemical modification of agarose. Although the insertion of acetyl groups leads to an increase in molecular weight, some degradation reactions can also occur. At low DA, this effect can overcome the first. Nevertheless, there is a tendency of

Table 3: Properties of agarose and O-acetyl agarose.

\begin{tabular}{l|ccc|cc}
\hline \multirow{2}{*}{ Sample } & \multicolumn{2}{|c|}{$\begin{array}{c}\text { Properties of agarose and } \\
\text { O-acetyl agarose soluble in DMSO }\end{array}$} & $\begin{array}{c}\text { Properties of the fraction of O-acetyl } \\
\text { agarose soluble in boiling water }\end{array}$ \\
\cline { 2 - 5 } & DA from NMR & $\begin{array}{c}{[\eta]} \\
(\mathbf{m L} / \mathbf{g})\end{array}$ & k' & DA & Stiffness of the gel \\
\hline Agarose & - & 112.7 & 0.45 & - & Very strong \\
AGA 2h & 0.07 & 58.2 & 0.40 & 0.08 & Weak \\
AGA 0.5h & 0.08 & 72.8 & 0.54 & -0.07 & Sery weak \\
AGA 20h & 0.11 & 98.2 & 0.42 & 0.06 & Weak \\
AGA 10h & 0.22 & 65.4 & 0.47 & 0.09 & Strong \\
\hline
\end{tabular}


increasing intrinsic viscosity when the DA increases or time of reaction decreases. This evolution is not understood up to now, but it may be related to some heterogeneity in the substitution.

Comparing the characteristics of $\mathrm{O}$-acetyl agarose gels (Table 3) with the corresponding intrinsic viscosities, and considering yet the partial solubility of the acetylated samples in water, the formation of weak gels for the acetylated samples with DA 0.07 , 0.08 and 0.22 can be explained by the reduction of gelling molecules concentration and to a decrease in molecular weight, disturbing the coil - helix conformational transition and the critical overlap concentration $\mathrm{C}^{*}$ for gelation respectively $\left(\right.$ as $\left.\mathrm{C}^{*} \sim[\eta]^{-1}\right)$.

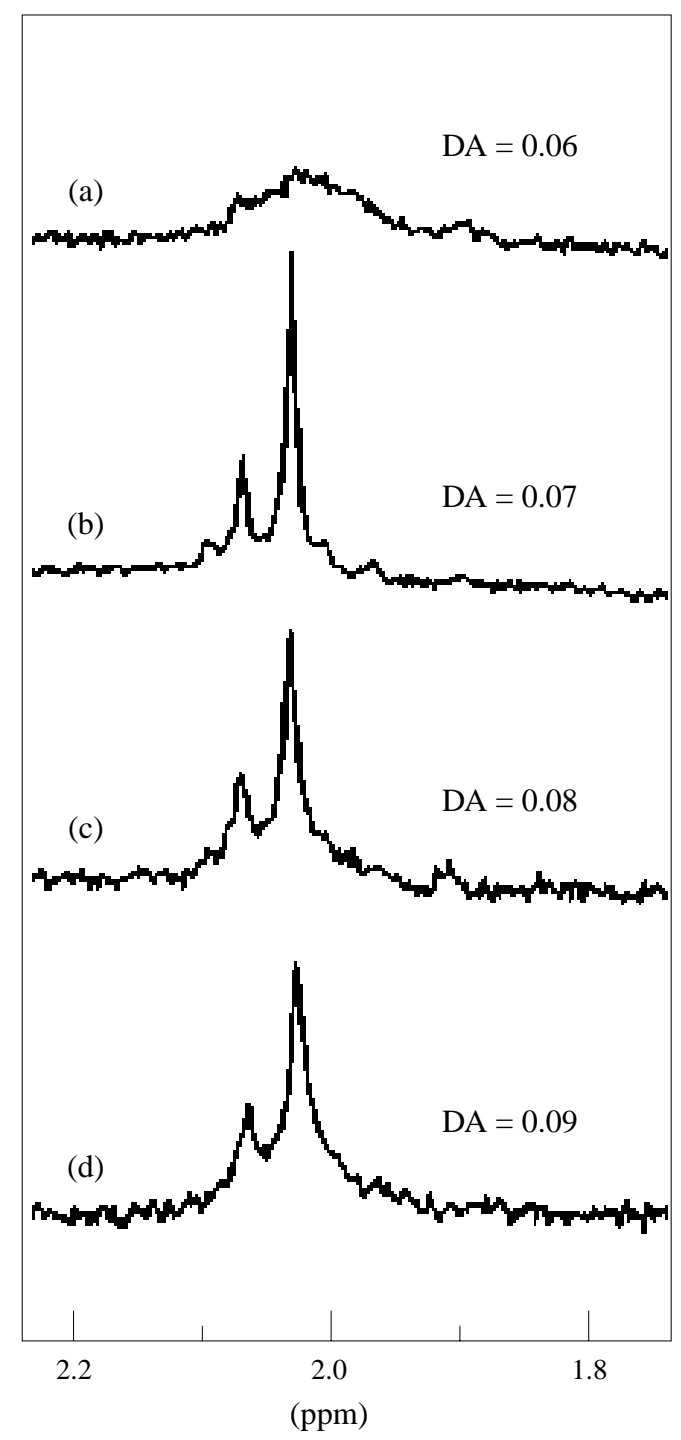

Figure 7. ${ }^{1} \mathrm{H}$ NMR spectra of O-acetyl agarose fractions solubilized in boiling water. (a) from $\mathrm{O}$-acetyl agarose $10 \mathrm{~h}$; (b) from $\mathrm{O}$-acetyl agarose $0.5 \mathrm{~h}$; (c) from $\mathrm{O}$-acetyl agarose $2 \mathrm{~h}$; (d) from O-acetyl agarose $4 \mathrm{~h}$.
The Huggins constant $\left(\mathrm{k}^{\prime}\right)$ determined from the equation $\eta_{\text {reduced }}=[\eta]+k^{\prime}[\eta]^{2} \mathrm{c}$, indicated good solubility of the polymers in DMSO, since k' was in the average range $0.3-0.5^{[35]}$.

Certainly, the results shown above are related to the pattern of distribution of acetyl groups in the backbone. Figure 7 shows the ${ }^{1} \mathrm{H}$ NMR of the water soluble fraction of $\mathrm{O}$-acetyl agarose samples in the range of the acetyl signal (2.2 to $1.8 \mathrm{ppm}$ ). These polymers presented at about the same DA of the original O-acetyl agarose samples after two hours reaction (Table 3), and a large signal at $2.02 \mathrm{ppm}$ without any signal at $1.94 \mathrm{ppm}$. This result means that the solubility in water is attributed only to molecules of low degree of acetylation i.e. a maximum degree of acetylation of 0.09 and that the distribution of acetyl groups in the polymer is not homogeneous, probably related to the heterogeneous reaction system used. In addition, the degree of solubility (water soluble fraction yield) decreases when the average degree of acetylation of the agarose increases.

\section{Conclusion}

O-acetyl agarose samples with low degree of acetylation were prepared in heterogeneous conditions. These polymers presented a reduction both in the boiling water solubility and in the gel ability even with a DA as low as 0.07 . On the other hand, the solubility in organic solvents, i.e. the hydrophobic character, was increased. A linear relation was obtained between the average degree of acetylation determined by $\mathrm{H}^{1} \mathrm{NMR}$ and the absorbance of carbonyl band in the Infrared spectra, indicating that the calibration curve proposed is a suitable way to determine the DA by Infrared.

\section{Acknowledgements}

The authors are much grateful to Conselho Nacional de Desenvolvimento Científico e Tecnológico (CNPq, CNPq-RHAE, CNPq-PIBIC) for financial support and to J. Brugnerotto (CERMAV) for his technical help.

\section{References}

1. Araki, C. - Proc. Int. Seaweed Symp., 5, p.3 (1966).

2. Meer, W. - "Agar", in: Handbook of Water-Soluble Gums and Resins, cap.7, Davidson, R.L. (ed.), McGraw Hill Inc., New York (1980). 
3. Andrade, C. T. \& Garcia, R. B. - "Agarose (Overview)", in: The Polymeric Materials Encyclopedia, p. 137, Salamone, J.C. (ed.), CRC Press Inc., Boca Raton (1996).

4. Kydonieus, A. G. - "Fundamental Concepts of Controlled Release", in: Controlled Release Technologies: Methods, Theory, and Applications, vol.1, p.1, Kydonieus, F. (ed.), CRC Press Inc., Boca Raton (1980).

5. Ferruti, P. \& Tanzi, M. C., "New Polymeric and Oligomeric Matrices as Drug Carriers" in: CRC Critical Reviews in Therapeutics, vol.2, p.175, CRC Press Inc., Boca Raton (1986).

6. Zhu, K.J.; Hendren, R.W.; Jensen, K. \& Putt, C.G. Macromolecules, 24, p.1736 (1991).

7. Nathan, A.; Bolikal, D.; Vyavahane, N.; Zalipsky, S. \& Koln, J. - Macromolecules, 25, p.4476 (1992).

8. Niekraszewicz, A. - Int. Polym. Sci. Technol., 21(3), p.90 (1994).

9. Storey, R.F. \& Hickey, T.P. - Polymer, 35(4), p.830 (1994).

10. Abe, H.; Doi, Y. \& Kumagai, Y., Macromolecules, 27, p.6012 (1994).

11. Löfgen, A.; Albertsson, A.-C.; Dubois, Ph.; Jérôme, R. \& Teyssié, Ph. - Macromolecules, 27, p.5556 (1994).

12. Hayashi, T.; Nakanishi, E.; Iizuka, Y.; Oya, M. \& Iwatsuki, M. - Eur. Polym. J., 30(9), p.1065 (1994).

13. Degêe, Ph.; Dubois, Ph.; Jérôme, R. \& Teyssié, Ph. J. Polym. Sci.: part A, 31, p.275 (1993).

14. Kemnitzer, J. E.; McCarthy, S. P. \& Gross, R. A. Macromolecules, 25, p.5927 (1992).

15. Kanesawa, Y.; Tanahashi, N. \& Saito, Y. - Polymer Degradation and Stability, 45, p.179 (1994).

16. Maulding, H. V. - J. Controlled Release, 6, p.167 (1987).

17. Oliveira, A. G.; Scarpa, M. V.; Bueno, J. H. F.\& Evangelista, R. C. - Rev. Ciênc. Farm.,14, p.37 (1992).

18. Remuñán-Lopez, C.; Lorenzo,M. L.; Portero, A.; Vila Jato, J. L. \& Alonso, M. J. - "Site-specific drug delivery using chitosan microparticles", in: Proceedings of the $7^{\text {th }}$ International Conference on
Chitin Chitosan and Euchis'97, p.600, Lyon France, set (1997).

19. van Dijk-Wolthuis, W. N. E.; Hoogeboom, J. A. M.; van Steenbergen, M. J.; Tsang, S. K. Y. \& Hennink, W. E. - Macromolecules, 30, p.4639 (1997).

20. McGee, J. P.; Singh, M.; Li, X.-M.; Qiu, H. \& O'Hagan, D. T. - J. Microencapsulation, 14(2), p.197 (1997).

21. Quintanar-Guerrero, D.; Allémann, E.; Fessi, H. \& Doelker, E. - Drug Dev. Ind. Pharm., 24(12), p.1113 (1998).

22. Mandal, T. K. - Drug Dev. Ind. Pharm., 24(7), p.623 (1998).

23. Giunchedi, P.; Genta, I.; Conti, B.; Muzzarelli, R. A. A. \& Conte, U. - Biomaterials, 19, p.157 (1998).

24. Genta, I.; Costantini, M.; Asti, A.; Conti, B. \& Montarani, L. - Carbohydr. Polym., 36, p.81 (1998).

25. Lee, S. C.; Oh, J. T.; Jang, M. H. \& Chung, S. I. - J. Controlled Release, 59, p. 123 (1999).

26. Andreo Filho, N. \& Oliveira, A.G. - Infarma, 9(1/5), p.18 (1999).

27. Cruaud, O.; Benita, S.; Benoit, J. P. - Int. J. Pharm., 177, p.247 (1999).

28. Dumitriu, S. - "Polymeric Biomaterials", Marcel Dekker Inc., New York (1994).

29. Goldberg, E. P.; Longo, W. \& Iwata, H., "Hydrophilic Albumin and Dextran Ion Exchange Microspheres for Localized Chemotherapy", in: Microsphere Drug Delivery, Elsevier, Amsterdam (1984).

30. Lahaye, M.; Revol J. F.; Rochas C.; Mc Lachlan J. \& Yaphe W. - Bot. Mar., 31, p.491 (1988).

31. Rochas, C.; Lahaye, M. \& Yaphe, W. - Bot Mar., 29, p.335 (1986).

32. Kamide, K.; Okajima, K. \& Saito, M. - Polym. J., 13, p.115 (1981).

33. Kamide, K. \& Okajima, K. - Polym . J., 13, p.127 (1981).

34. Method ASTM D871-72 - American Society for Testing and Materials, part 21 (1975).

35. Tanford, C. - "Physical Chemistry of Macromolecules", John Wiley \& Sons, New York, 1961.

Received: 11/04/00

Accepted: $29 / 09 / 00$ 